\title{
Prospective study on the effects of orthotic treatment for medial knee osteoarthritis in Chinese patients: clinical outcome and gait analysis
}

\author{
Henry CH Fu, Chester WH Lie *, TP Ng, KW Chen, CY Tse, WH Wong
}

\section{A B S T R A C T}

Objective: To evaluate the effectiveness of various orthotic treatments for patients with isolated medial compartment osteoarthritis.

Design: Prospective cohort study with sequential interventions.

Setting: University-affiliated hospital, Hong Kong.

Patients: From December 2010 to November 2011, 10 patients with medial knee osteoarthritis were referred by orthopaedic surgeons for orthotic treatment. All patients were sequentially treated with flat insole, lateral-wedged insole, lateralwedged insole with subtalar strap, lateral-wedged insole with arch support, valgus knee brace, and valgus knee brace with lateral-wedged insole with arch support for 4 weeks with no treatment break. Three-dimensional gait analysis and questionnaires were completed after each orthotic treatment.

Main outcome measures: The Western Ontario and McMaster Universities Arthritis Index (WOMAC), visual analogue scale scores, and peak and mean knee adduction moments.

Results: Compared with pretreatment, the lateralwedged insole, lateral-wedged insole with arch support, and valgus knee brace groups demonstrated significant reductions in WOMAC pain score (19.1\%, $\mathrm{P}=0.04$; $18.2 \%, \mathrm{P}=0.04$; and $20.4 \%, \mathrm{P}=0.02$, respectively). The lateral-wedged insole with arch support group showed the greatest reduction in visual analogue scale score compared with pretreatment

This article was published on 10 Mar 2015 at www.hkmj.org. at $24.1 \%(\mathrm{P}=0.004)$. Addition of a subtalar strap to

subtalar strap) did not produce significant benefit when compared with the lateral-wedged insole alone. The valgus knee brace with lateral-wedged insole with arch support group demonstrated an additive effect with a statistically significant reduction in WOMAC total score $(-26.7 \%, \mathrm{P}=0.01)$. Compliance with treatment for the isolated insole groups were all over $90 \%$, but compliance for the valgus knee brace-associated groups was only around 50\%. Gait analysis indicated statistically significant reductions in peak and mean knee adduction moments in all orthotic groups when compared with a flat insole.

Conclusions: These results support the use of orthotic treatment for early medial compartment knee osteoarthritis.

\section{Hong Kong Med J 2015;21:98-106}

DOI: $10.12809 / \mathrm{hkmj} 144311$

\author{
${ }^{1} \mathrm{HCH}$ Fu, MB, BS, MMedSc \\ ${ }^{2}$ CWH Lie *, FRCS (Edin), FHKAM (Orthopaedic Surgery) \\ ${ }^{3}$ TP Ng, FRCS (Edin), FHKAM (Orthopaedic Surgery) \\ ${ }^{4} \mathrm{KW}$ Chen, BSc \\ ${ }^{4} \mathrm{CY}$ Tse, BSc \\ ${ }^{4}$ WH Wong, Diploma in Prosthetics and Orthotics
}

${ }^{1}$ Department of Orthopaedics and Traumatology, Queen Mary Hospital, Pokfulam, Hong Kong

2 Department of Orthopaedics and Traumatology, Kwong Wah Hospital, Yaumatei, Hong Kong

Private Practice, Hong Kong

${ }^{4}$ Department of Prosthetics and Orthotics, Queen Mary Hospital, Pokfulam, Hong Kong

* Corresponding author: chesterliewh@gmail.com

\footnotetext{
New knowledge added by this study

- Our data support the use of the lateral-wedged insole with arch support and valgus knee brace in the management of medial compartment osteoarthritis of the knee; however, compliance with the valgus knee brace is fair. Gait analysis showed that both supports can reduce the knee adduction moment during walking.

Implications for clinical practice or policy

- Lateral-wedged insoles with arch support and valgus knee brace can be considered for patients with medial compartment osteoarthritis of the knee.
}

\section{Introduction}

Osteoarthritis of the knee is the commonest type of arthritis affecting the geriatric population.
Conservative treatment with physiotherapy and analgesics provides temporary relief of symptoms, yet surgical intervention such as high tibial 
osteotomy, unicompartmental knee replacement, or total knee replacement is a major undertaking and not without risk. ${ }^{1,2}$ The medial compartment is more commonly affected than the lateral compartment in osteoarthritis $(67 \%$ and $17 \%$, respectively $){ }^{3}$ Varus alignment of the lower limbs increases the risk of incident knee osteoarthritis and also increases the risk of disease progression in patients with osteoarthritis. ${ }^{4}$ Apart from static lower limb alignment, dynamic varus thrust during the gait cycle is also independently associated with osteoarthritis progression in the knee. ${ }^{5}$ Knee adduction moment (KAM) is an indirect means to assess varus thrust during the gait cycle. Previous studies have proven the validity of KAM for prediction of clinical and radiological osteoarthritis progression. ${ }^{6}$

Orthotic treatment can alter loading to the knee in the hope of reducing symptoms and disease progression. Biomechanical studies have demonstrated a small effect size in reduction of KAM with a valgus knee brace $\mathrm{e}^{7-10}$ and lateral-wedged insoles. ${ }^{11-14}$ This study is the first to sequentially evaluate the clinical outcomes and gait analyses of different orthotic treatments in Chinese patients with medial compartment osteoarthritis.

\section{Methods}

\section{Patients}

From December 2010 to November 2011, 18 patients with isolated medial osteoarthritis of the knee were referred by orthopaedic surgeons to the Department of Prosthetics and Orthotics at Queen Mary Hospital for orthotic treatment.

The inclusion criteria were age older than 50 years and a diagnosis of osteoarthritis according to the American College of Rheumatology criteria. ${ }^{15}$ The predominant symptom needed to be medial knee pain. Radiographical features needed to include varus knee alignment and osteoarthritis of Kellgren-Lawrence grade 2 or above over the medial compartment. ${ }^{16}$

Our study population comprised patients with isolated medial compartment osteoarthritis, while patients with predominant lateral compartment or patellofemoral joint symptoms or those with radiographical features of osteoarthritis of Kellgren-Lawrence grade 2 or above over the lateral compartment or patellofemoral joint were excluded.

Patients with previous knee surgery, fixed flexion deformity of $>10^{\circ}$, hip or ankle pathology, required a walking aid, or had morbid obesity (body mass index, $>40 \mathrm{~kg} / \mathrm{m}^{2}$ ), a dermatological condition, or peripheral vascular disease were also excluded.

This was a non-randomised prospective cohort study with a cross-over design. All 10 patients were sequentially treated with a flat insole (FI), lateralwedged insole (LW), lateral-wedged insole with

\section{矯形治療對於內側膝退化性關節炎華籍患者的效} 果：臨床結果和步態分析的前瞻性研究

傅俊謙、李威鴻、吳子培、陳金偉、謝靜怡、黃偉興

目的：評估各種矯形治療對於內側膝單室退化性關節炎患者的效果。

設計：連續性干預的前瞻性隊列研究。

安排：香港一所大學附屬醫院。

患者：從2010年12月到2011年11月，由骨科醫生轉介須進行矯正治 療的內側膝退化性關節炎共有 10 例。所有患者均連續四週逐一接受 以下治療：平鞋熱、外側楔型鞋熱、以綁帶將外側楔型鞋熱綁在腳底 下、外側楔型鞋熱搭配足弓熱、護膝, 以及外側楔型鞋熱搭配足弓熱 並加上護膝。每次治療後均進行三維步態分析, 並讓患者填寫問卷。

主要結果測量：西安大略和麥克馬斯特大學關節炎指數（WOMAC）、 視覺模擬量表評分, 以及峰值和平均膝蓋內收力矩。

結果：與治療前相比, 外側楔型鞋熱、外側楔型鞋熱搭配足弓熱 和護膝治療的WOMAC疼痛子量指數顯著減少 (其比率和 $\mathrm{P}$ 值依次 為：19.1\%，P=0.04；18.2\%，P=0.04；20.4\%，P=0.02）。與治療前 相比, 外側楔型鞋熱搭配足弓熱治療的視覺模擬量表得分改善幅度最 大 $(24.1 \% ; \mathrm{P}=0.004)$ 。至於以綁帶將外側楔型鞋熱綁在腳底下的治 療, 與單獨使用外側楔型鞋熱相比, 並沒有明顯改善。外側楔型鞋熱 搭配足弓熱並加上護膝的治療得到累加效應, 其WOMAC總指數顯著 下降 $(-26.7 \%, \mathrm{P}=0.01)$ 。所有使用外側楔型鞋熱的病人依從性均超 過九成, 可惜搭配護膝治療的依從性只有五成左右。步態分析顯示與 平鞋熱比較, 所有治療的峰值和平均膝蓋內收力矩均顯著下降。

結論：以上結果支持應在早期使用矯形治療醫治內側膝退化性關節 炎。

subtalar strap (LW+SS), lateral-wedged insole with arch support (LWAS), valgus knee brace (VKB), and valgus knee brace with lateral-wedged insole with arch support (VKB+LWAS). The FI group acted as a control during gait analysis to mimic normal walking. The designs of the orthotics are shown in Figure 1. The insoles were custom-made in the Department of Prosthetics and Orthotics at Queen Mary Hospital, while the Unloader valgus knee braces (Össur hf, Reykjavik, Iceland) were ordered for each patient after measurement. Each of the orthotic treatments was prescribed for 4 weeks and each patient underwent 24 weeks of treatment to use all six orthotics.

For subjective clinical outcomes, pain scores using the visual analogue scale (VAS) and version 3.1 of the Chinese-validated Western Ontario and McMaster Universities Arthritis Index (WOMAC) were measured. The VAS, with a scale from 0 to 10 , was used purely for pain severity. The WOMAC score was ascertained by a self-administered questionnaire consisting of 24 items and subdivided into three categories: pain (5 items), stiffness (2 items), and difficulty performing daily activities (17 


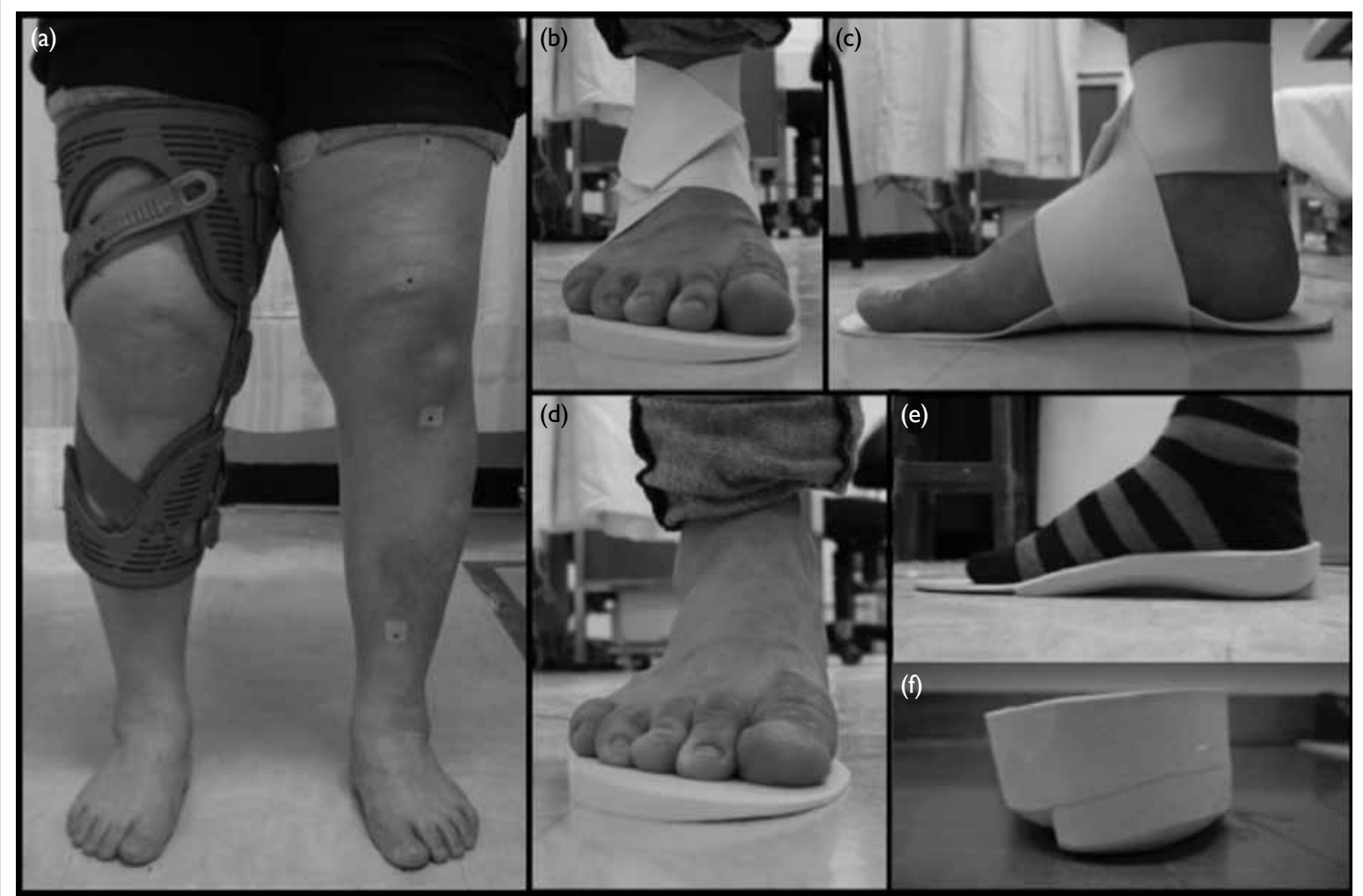

FIG I. Various orthotic treatments: (a) valgus knee brace, (b and c) lateral-wedged insole with subtalar strap, (d) lateral-wedged insole, and (e and $f$ ) lateral-wedge with arch support

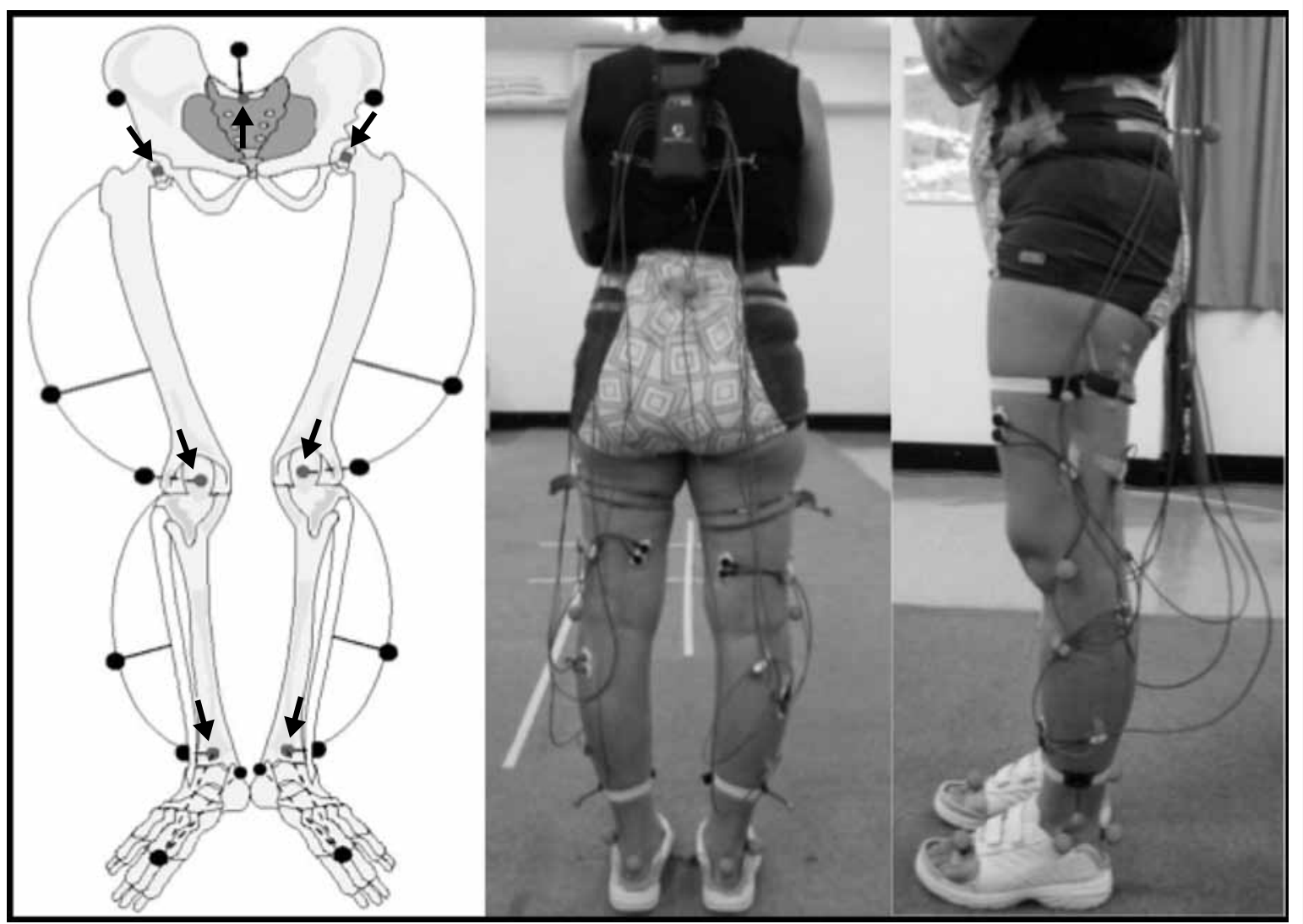

FIG 2. Placement of retro-reflective markers (arrows) for gait analysis 
items). Analgesic use (number of times required per week) was also compared. Pretreatment and interval assessments were completed after each orthotic treatment. Paired $t$ test was used for analysis.

\section{Gait analysis}

Three-dimensional gait analyses were performed for each patient both before and during use of each orthotic treatment at the gait laboratory at the Duchess of Kent Children's Hospital, Hong Kong, which is an affiliated hospital within the same cluster as Queen Mary Hospital.

Fifteen retro-reflective markers were placed according to the Plug in Gait model (Vicon Industries, Inc, Edgewood [NY], US) as shown in Figure 2. The markers were placed at the bilateral anterior superior iliac spines, midway between the posterior superior iliac spine, lateral epicondyle of the knee, lateral lower third of the thigh, lateral malleolus, lower third of the shin, second metatarsal head, and calcaneus at the level of the second metatarsal head. Three-dimensional positions of the markers and kinematic data were collected by six cameras using the 370 motion analysis system (Vicon Industries, Inc) at a sampling frequency of $60 \mathrm{~Hz}$. Kinetic data were collected using the 370 motion analysis system synchronised with a multicomponent force platform (Kistler, Winterthur, Switzerland) at $60 \mathrm{~Hz}$.

Peak and mean KAMs during the stance phase of the gait cycle were measured. Mechanical alignment throughout the gait cycle was derived from the hip centre, knee centre, and ankle centre from the retro-reflective markers. After data collection from the gait analysis laboratory, data were analysed jointly by orthopaedic surgeons and prosthetic and orthotic specialists who had a

TABLE I. Comparison of subjective pretreatment and post-treatment scores for various orthotics

\begin{tabular}{|c|c|c|c|c|c|}
\hline & \multicolumn{4}{|c|}{ WOMAC } & \multirow[t]{2}{*}{ VAS $(1-10)$} \\
\hline & Part A (Pain) & $\begin{array}{c}\text { Part B } \\
\text { (Stiffness) }\end{array}$ & $\begin{array}{l}\text { Part C (Activities } \\
\text { of daily living) }\end{array}$ & Total & \\
\hline \multicolumn{6}{|l|}{ Pretreatment } \\
\hline Mean & 54.4 & 54.4 & 48.8 & 48.1 & 5.5 \\
\hline \multicolumn{6}{|l|}{ Flat insole } \\
\hline Mean & 48.6 & 47.3 & 46.4 & 45.0 & 5.5 \\
\hline \% Reduction & -10.6 & -12.2 & -4.8 & -6.5 & -0.86 \\
\hline$P$ value & 0.11 & 0.17 & 0.41 & 0.25 & 0.82 \\
\hline \multicolumn{6}{|c|}{ Lateral-wedged insole } \\
\hline Mean & 44.0 & 43.1 & 47.8 & 44.4 & 5 \\
\hline \% Reduction & -19.1 & -20.0 & -2.0 & -7.8 & -10.3 \\
\hline$P$ value & 0.04 & 0.10 & 0.72 & 0.23 & 0.14 \\
\hline \multicolumn{6}{|c|}{ Lateral-wedged insole with subtalar strap } \\
\hline Mean & 47.3 & 43.8 & 47.2 & 45.1 & 4.9 \\
\hline \% Reduction & -13.0 & -18.7 & -3.3 & -6.3 & -11.2 \\
\hline$P$ value & 0.12 & 0.09 & 0.69 & 0.43 & 0.15 \\
\hline \multicolumn{6}{|c|}{ Lateral-wedged insole with arch support } \\
\hline Mean & 44.5 & 45.5 & 44.6 & 42.8 & 4.2 \\
\hline$\%$ Reduction & -18.2 & -15.5 & -8.5 & -11.1 & -24.1 \\
\hline$P$ value & 0.04 & 0.11 & 0.25 & 0.14 & 0.004 \\
\hline \multicolumn{6}{|c|}{ Valgus knee brace } \\
\hline Mean & 43.3 & 47.9 & 46.1 & 43.6 & 4.7 \\
\hline$\%$ Reduction & -20.4 & -11.1 & -5.6 & -9.3 & -15.5 \\
\hline$P$ value & 0.02 & 0.15 & 0.56 & 0.28 & 0.04 \\
\hline \multicolumn{6}{|c|}{$\begin{array}{l}\text { Valgus knee brace with lateral-wedged } \\
\text { insole with arch support }\end{array}$} \\
\hline Mean & 38.4 & 43.7 & 35.9 & 35.3 & 4.3 \\
\hline \% Reduction & -29.4 & -18.8 & -26.4 & -26.7 & -22.4 \\
\hline$P$ value & 0.001 & 0.02 & 0.002 & 0.001 & 0.004 \\
\hline
\end{tabular}

Abbreviations: VAS = visual analogue scale score;WOMAC = Western Ontario and McMaster Universities Arthritis Index 
TABLE 2. Mean knee adduction moment for various orthotic treatments

\begin{tabular}{lcccc}
\hline & Mean KAM (Nm/kg) & Standard deviation & \% Reduction compared with FI & P value \\
\hline FI & 0.201 & 0.071 & - & -18.1 \\
LW & 0.164 & 0.069 & -17.6 & 0.01 \\
LW+SS & 0.165 & 0.064 & -9.7 & 0.02 \\
LWAS & 0.181 & 0.071 & -15.5 & 0.001 \\
VKB & 0.170 & 0.072 & -16.3 & 0.003 \\
\hline VKB+LWAS & 0.168 & 0.071 & & \\
\hline
\end{tabular}

Abbreviations: FI = flat insole; KAM = knee adduction moment; LW = lateral-wedged insole; LWAS = lateral-wedged insole with arch support; SS = subtalar strap; $\mathrm{VKB}=$ valgus knee brace

TABLE 3. Peak knee adduction moment for various orthotic treatments

\begin{tabular}{lcccc}
\hline & Peak KAM (Nm/kg) & Standard deviation & \% Reduction compared with FI & P value \\
\hline FI & 0.568 & 0.203 & - & - \\
LW & 0.494 & 0.168 & -13.1 & 0.001 \\
LW+SS & 0.461 & 0.170 & -18.8 & 0.002 \\
LWAS & 0.491 & 0.171 & -13.7 & 0.003 \\
VKB & 0.461 & 0.161 & -18.9 & $<0.001$ \\
VKB+LWAS & 0.449 & 0.167 & -21.0 & $<0.001$ \\
\hline
\end{tabular}

Abbreviations: $\mathrm{Fl}=$ flat insole; $\mathrm{KAM}=$ knee adduction moment; LW = lateral-wedged insole; LWAS = lateral-wedged insole with arch support; SS = subtalar strap; $\mathrm{VKB}=$ valgus knee brace

background in biomedical engineering. Gait analysis comparison was made with the FI group and baseline control data. An assumption was made that the flat insole would not alter the knee kinematics. The control data from the gait laboratory consisted of 47 aged-matched healthy participants with normal gait pattern.

Paired $t$ tests were used for comparison of different gait parameters between the orthotic type and baseline measurement.

\section{Results}

Eighteen patients (36 knees) were initially recruited into our study. Nineteen knees of 10 patients completed the study, and the remaining eight patients withdrew for personal reasons. Of the 10 patients, nine had bilateral disease and one had unilateral disease. Ten knees were right knees and nine were left knees. There were six women and four men. The mean age of the patients was 56 years (range, 51-65 years). The pretreatment motion arc ranged from $65^{\circ}$ to $140^{\circ}$ (mean, $122^{\circ}$ ).

The changes in mean WOMAC and VAS scores for various orthotic treatments and their comparison with pretreatment scores are shown in Table 1 . The results of mean and peak KAMs throughout the gait cycle with different orthotics are shown in Figure 3a. The mean and peak KAMs for each orthotic are shown in Tables 2 and 3, respectively. Figure 3b shows the knee mechanical alignment derived from the hip centre, knee centre, and ankle centre. The initial 65\% of the gait cycle represents the stance phase and the later $35 \%$ is the swing phase. Compliance with the orthotic treatments is shown in Figure 4.

The LW group demonstrated a significant reduction of $19.1 \%$ in the WOMAC pain score $(\mathrm{P}=0.04)$. Reductions in total and other WOMAC subscale scores, VAS score, and analgesic requirement were observed, but none were statistically significant. Mean and peak KAMs were reduced by $18.1 \%$ and $13.1 \%(\mathrm{P}<0.05)$, respectively, when compared with the FI group. The compliance rate was $94.7 \%$ of total walking time.

With the addition of subtalar strapping in the hope of increasing the effectiveness of the lateral wedge, the LW+SS group demonstrated a greater reduction of peak KAM (18.8\%), but a smaller degree of reduction in mean KAM $(17.6 \%)[\mathrm{P}<0.05]$. The net effect of $\mathrm{LW}+\mathrm{SS}$ did not confer any statistically significant reduction in VAS score, WOMAC score, or analgesic requirement when compared with the pretreatment scores. The compliance rate for the $\mathrm{LW}+\mathrm{SS}$ group was $94.7 \%$ of total walking time.

The LWAS group demonstrated statistically significant reduction in VAS score of $24.1 \%(\mathrm{P}=0.004)$ and WOMAC pain score of $18.2 \%(\mathrm{P}=0.04)$. Mean and peak KAMs were also significantly reduced by $9.7 \%$ and $13.7 \%$, respectively $(\mathrm{P}<0.05)$. The degree of reduction in VAS score was greatest in 
the LWAS group when compared with the LW and $\mathrm{LW}+\mathrm{SS}$ groups. Score of VAS may be a more reliable predictor of actual symptom improvement than the WOMAC pain score. The compliance rate was also greatest for the LWAS group at $97.4 \%$ of total walking time. No significant difference in analgesic requirement was observed.

With respect to mean mechanical alignment, as shown in Figure $3 b$, all the insole groups (LW, $\mathrm{LW}+\mathrm{SS}$, and LWAS) showed lower varus angle throughout the stance phase. The stance phase is the symptomatic phase when the knee is under loading.

The VKB group showed a statistically significant reduction in VAS score and WOMAC pain score of $15.5 \%(\mathrm{P}=0.04)$ and $20.4 \%(\mathrm{P}=0.02)$, respectively. The WOMAC total score and other subscale scores showed some reductions, but these were not statistically significant. The analgesic requirement was also significantly reduced from 1.5 days/week pretreatment to 0.5 days/week posttreatment $(\mathrm{P}=0.04)$. Mean and peak KAMs were reduced by $15.5 \%$ and $18.9 \%$, respectively $(\mathrm{P}<0.05)$. Mechanical alignment, as seen in Figure 3b, showed reduced varus angulation during the early stance phase. The interval between $15 \%$ and $20 \%$ of the gait cycle, representing the heel strike to mid-stance phase, was shown to have reduced the varus angle when compared with baseline. The varus angle remained constant throughout the stance phase, which was related to restricted motion of the knee inside the brace. Compliance was significantly lower than that for any of the insole groups at $54.5 \%$ of the total walking time. The low compliance rate was likely due to the bulky size of the valgus knee brace causing skin discomfort, especially in the hot and humid climate in this region.

The LWAS seemed to be the best insole treatment for pain relief and improvement in VAS score, so we further evaluated the combination effects of the VKB and LWAS treatments. Additive effects were observed with combined treatment. The $\mathrm{VKB}+\mathrm{LWAS}$ group showed significant reductions in VAS score, as well as WOMAC total and all subscale scores. Score of VAS reduced by $22.4 \%(\mathrm{P}=0.004)$, WOMAC pain score reduced by $29.4 \%(\mathrm{P}=0.001)$, WOMAC stiffness score reduced by $18.8 \%(\mathrm{P}=0.02)$, WOMAC activities of daily living score reduced by 26.4\% $(\mathrm{P}=0.002)$, and WOMAC total score reduced by $26.7 \%(\mathrm{P}=0.001)$. The extent of reduction in the WOMAC total and subscale scores for this group was the greatest of the treatment groups. The analgesic requirement was also significantly reduced from 1.5 days/week pretreatment to 0.6 days/week posttreatment $(\mathrm{P}=0.04)$. Peak KAM showed the greatest reduction of all the orthotic groups of $21.0 \%$, while mean KAM showed moderate reduction of $16.3 \%$ $(\mathrm{P}<0.05)$. With regard to the mechanical alignment, reduction in varus angle was observed in the early

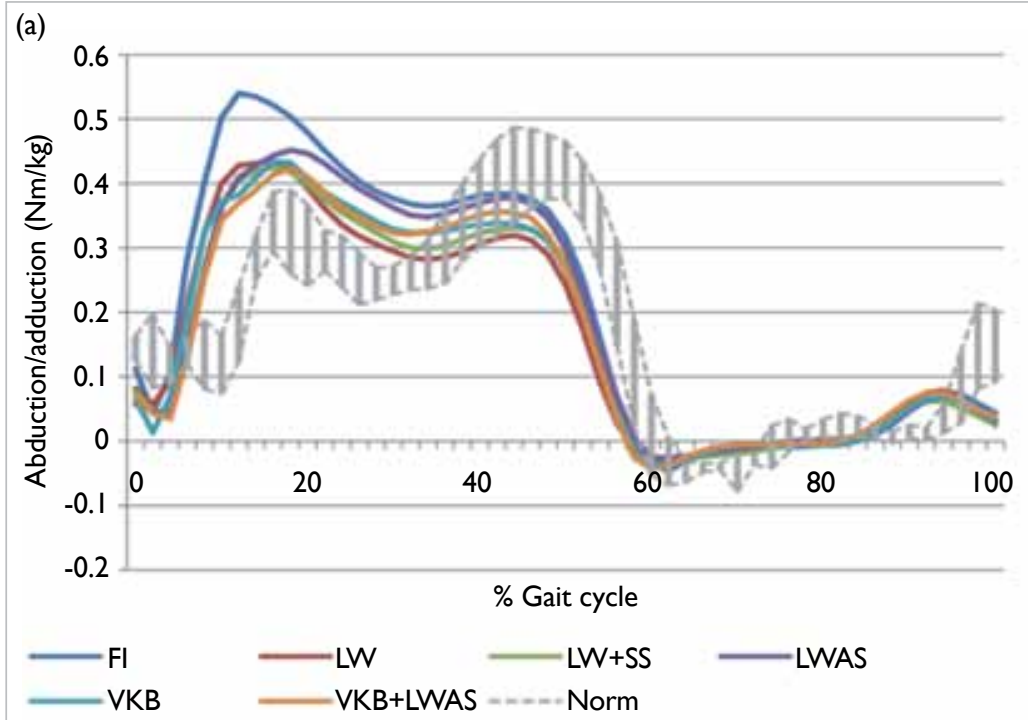

(b)

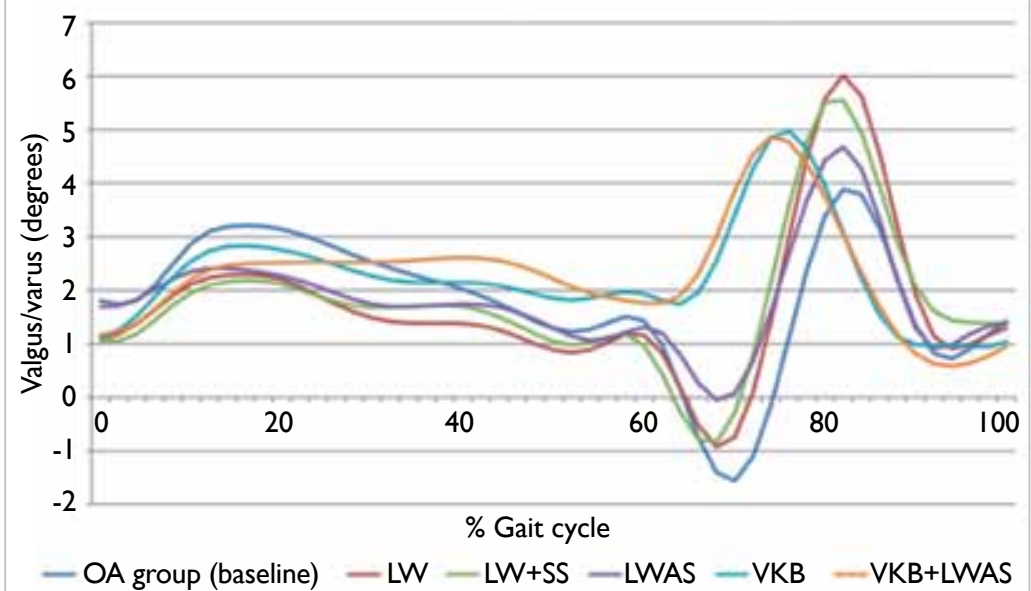

FIG 3. (a) Comparison of knee adduction moments with different orthotic treatments throughout the gait cycle. (b) Comparison of mean mechanical alignment with different orthotic treatments

Abbreviations: $\mathrm{FI}$ = flat insole; $\mathrm{LW}=$ lateral-wedged insole; $\mathrm{LWAS}=$ lateral-wedged insole with arch support; Norm = normal; OA = osteoarthritis; $\mathrm{SS}=$ subtalar strap; $\mathrm{VKB}=$ valgus $\mathrm{knee}$ brace

stance phase, as in the isolated VKB group. The compliance, as expected, was lowest among all the treatment arms with only $49.1 \%$ of total walking time.

\section{Discussion}

The current literature recommendations for orthotic treatment for medial compartment knee osteoarthritis are still varied. In a guideline by the Osteoarthritis Research Society International (OARSI), insoles were concluded to be of benefit to reduce pain and improve ambulation in knee osteoarthritis. ${ }^{17}$ However, in another guideline by the American Academy of Orthopaedic Surgeons 


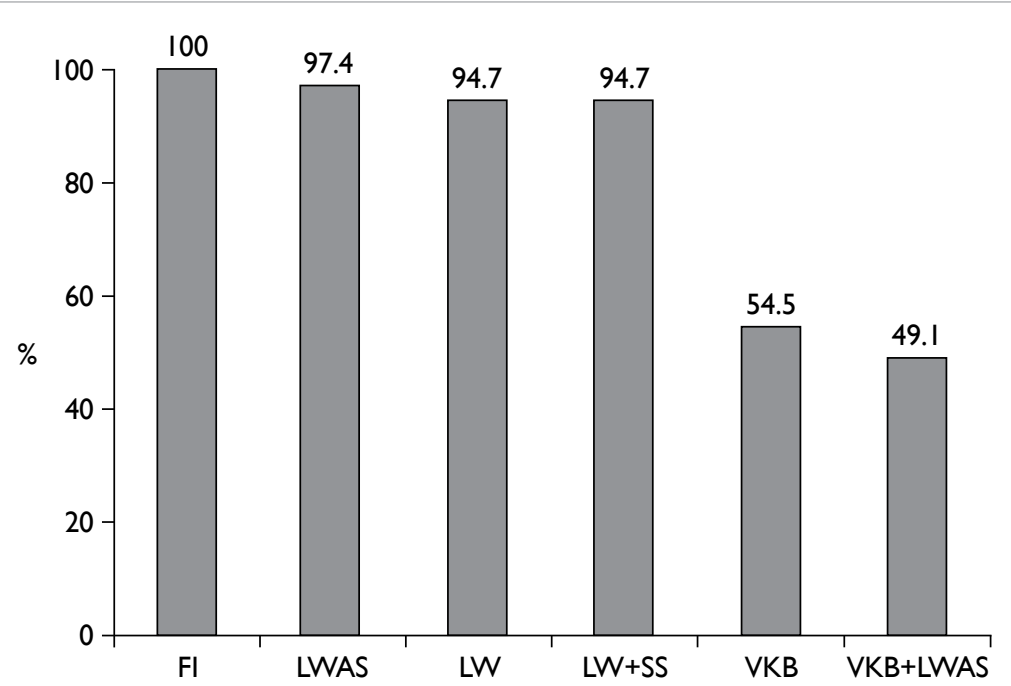

FIG 4. Compliance with orthotic treatments expressed as percentage of total walking time

Abbreviations: $\mathrm{FI}=$ flat insole; $\mathrm{LW}=$ lateral-wedged insole; $\mathrm{LWAS}=$ lateral-wedged insole with arch support; SS = subtalar strap; VKB = valgus knee brace knee osteoarthritis.

Knee bracing acts by inducing a valgus force by the three-point bending principle. The OARSI guideline suggests that knee bracing could reduce pain, improve stability, and reduce the risk of fall in patients with mild-to-moderate osteoarthritis or valgus instability. ${ }^{17}$ However, the guideline from the AAOS could not conclude for or against the use of valgus-directed bracing. ${ }^{18}$ Advantages of knee bracing include avoidance of surgery and the potential surgical complications, while the disadvantages include compliance and the cost of manufacturing the brace. ${ }^{28} \mathrm{~A}$ randomised controlled trial by Brouwer et $\mathrm{al}^{29}$ compared three treatment groups of valgus knee brace plus medical treatment, insole plus medical treatment, and medical treatment alone. The brace plus medical treatment was shown to have borderline benefit compared to medical treatment alone in terms of pain score and function. ${ }^{29}$ These findings concur with our study result of improved WOMAC pain subscale score and reduced analgesic requirement with valgus knee brace when compared to pretreatment scores. From the kinetics perspective, Pollo et $\mathrm{al}^{7}$ were able to demonstrate reduction in net external KAM by $13 \%$. Our gait analysis model was able to reproduce reduction in mean KAM by $18.9 \%$. Despite the potential benefits from valgus knee brace, compliance remains a major drawback. With a compliance rate of $54.5 \%$, many of our patients claimed that they did not wear the braces outdoors due to skin discomfort in the hot and humid climate. Our evidence would suggest valgus knee brace is suitable for selected patients with mild knee osteoarthritis, with consideration of the problem with fitting and compliance.

Our current study was among the few to evaluate the effects of combination orthotic treatment with valgus knee brace and lateralwedged insole with arch support. The VKB+LWAS group was the only one to demonstrate significant reductions in WOMAC total and all subscale scores, analgesic use, and KAM when compared with pretreatment. These results further reiterate the dose-response relationship in reducing KAM to achieve improvement in objective knee scores. Despite these findings, the poor compliance rate would render this orthotic treatment less advisable.

\section{Limitations}

Limitations of our study included a small sample size, selection bias, self-selection bias, and a short follow-up period. Similar studies of less than 20 patients are seen in many studies of gait analysis..$^{30-32}$ A larger sample size would provide a higher power to determine the statistical significance in more of the evaluated parameters. Compliance with orthotic treatment, in particular with the valgus knee brace, was another concern. Confounding factors in our 
study included the frequency of weight-bearing activities, which could be difficult to quantify.

This was a cross-over study, with all patients having to be treated sequentially with all six orthotic combinations. The advantages are an economy of sample size without the need to account for heterogeneity of the patient groups. The disadvantages of the design include lack of a treatment break and lack of randomisation in the treatment sequence. Scores of VAS reported by elderly people may also be inaccurate.

\section{Conclusions}

Knee osteoarthritis continues to pose a significant burden to our community with its ageing population and increased incidence of obesity. While operative treatments are not without risk, orthotic treatment also has its advantages and disadvantages. Our current study was able to demonstrate from subjective scores and gait analysis that orthotic treatment can alter knee loading and alleviate symptoms. The lateral-wedged insole with arch support is optimal, while valgus knee brace is equally effective, with fair compliance. Further studies with a larger sample size are required to evaluate the effectiveness in the long term.

\section{References}

1. Knutson K, Lindstrand A, Lidgren L. Survival of knee arthroplasties. A nation-wide multicentre investigation of 8000 cases. J Bone Joint Surg Br 1986;68:795-803.

2. Swedish Knee Arthroplasty Registry. SKAR Annual Report; 2011.

3. Ledingham J, Regan M, Jones A, Doherty M. Radiographic patterns and associations of osteoarthritis of the knee in patients referred to hospital. Ann Rheum Dis 1993;52:5206.

4. Sharma L, Song J, Dunlop D, et al. Varus and valgus alignment and incident and progressive knee osteoarthritis. Ann Rheum Dis 2010;69:1940-5.

5. Chang A, Hayes K, Dunlop D, et al. Thrust during ambulation and the progression of knee osteoarthritis. Arthritis Rheum 2004;50:3897-903.

6. Birmingham TB, Hunt MA, Jones IC, Jenkyn TR, Giffin JR. Test-retest reliability of the peak knee adduction moment during walking in patients with medial compartment knee osteoarthritis. Arthritis Rheum 2007;57:1012-7.

7. Pollo FE, Otis JC, Backus SI, Warren RF, Wickiewicz TL. Reduction of medial compartment loads with valgus bracing of the osteoarthritic knee. Am J Sports Med 2002;30:414-21.

8. Lindenfeld TN, Hewett TE, Andriacchi TP. Joint loading with valgus bracing in patients with varus gonarthrosis. Clin Orthop Relat Res 1997;344:290-7.

9. Pagani $\mathrm{CH}$, Böhle C, Potthast W, Brüggemann GP. Shortterm effects of a dedicated knee orthosis on knee adduction moment, pain, and function in patients with osteoarthritis. Arch Phys Med Rehabil 2010;91:1936-41.

10. Toriyama M, Deie M, Shimada N, et al. Effects of unloading bracing on knee and hip joints for patients with medial compartment knee osteoarthritis. Clin Biomech (Bristol, Avon) 2011;26:497-503.

11. Hinman RS, Bowles KA, Bennell KL. Laterally wedged insoles in knee osteoarthritis: do biomechanical effects decline after one month of wear? BMC Musculoskelet Disord 2009;10:146.

12. Fantini Pagani $\mathrm{CH}$, Hinrichs $\mathrm{M}$, Brüggemann GP. Kinetic and kinematic changes with the use of valgus knee brace and lateral wedge insoles in patients with medial knee osteoarthritis. J Orthop Res 2012;30:1125-32.

13. Butler RJ, Marchesi S, Royer T, Davis IS. The effect of a subject-specific amount of lateral wedge on knee mechanics in patients with medial knee osteoarthritis. J Orthop Res 2007;25:1121-7.

14. Kakihana W, Akai M, Nakazawa K, Naito K, Torii S. Inconsistent knee varus moment reduction caused by a lateral wedge in knee osteoarthritis. Am J Phys Med Rehabil 2007;86:446-54.

15. Belo JN, Berger MY, Koes BW, Bierma-Zeinstra SM. The prognostic value of the clinical ACR classification criteria of knee osteoarthritis for persisting knee complaints and increase of disability in general practice. Osteoarthritis Cartilage 2009;17:1288-92.

16. Kellgren JH, Lawrence JS. Radiological assessment of osteo-arthrosis. Ann Rheum Dis 1957;16:494-502.

17. Zhang W, Moskowitz RW, Nuki G, et al. OARSI recommendations for the management of hip and knee osteoarthritis, Part II: OARSI evidence-based, expert consensus guidelines. Osteoarthritis Cartilage 2008;16:137-62.

18. Jevsevar DS, Brown GA, Jones DL, et al. The American Academy of Orthopaedic Surgeons evidence-based guideline on: treatment of osteoarthritis of the knee, 2nd edition. J Bone Joint Surg Am 2013;95:1885-6.

19. Yasuda K, Sasaki T. The mechanics of treatment of the osteoarthritic knee with a wedged insole. Clin Orthop Relat Res 1987;215:162-72.

20. Shimada S, Kobayashi S, Wada M, et al. Effects of disease severity on response to lateral wedged shoe insole for medial compartment knee osteoarthritis. Arch Phys Med Rehabil 2006;87:1436-41.

21. Toda Y, Tsukimura N, Kato A. The effects of different elevations of laterally wedged insoles with subtalar strapping on medial compartment osteoarthritis of the knee. Arch Phys Med Rehabil 2004;85:673-7.

22. Sasaki T, Yasuda K. Clinical evaluation of the treatment of osteoarthritic knees using a newly designed wedged insole. Clin Orthop Relat Res 1987;221:181-7.

23. Maillefert JF, Hudry C, Baron G, et al. Laterally elevated wedged insoles in the treatment of medial knee osteoarthritis: a prospective randomized controlled study. Osteoarthritis Cartilage 2001;9:738-45.

24. Baker K, Goggins J, Xie H, et al. A randomized crossover trial of a wedged insole for treatment of knee osteoarthritis. Arthritis Rheum 2007;56:1198-203.

25. Toda Y, Tsukimura N. A six-month followup of a randomized trial comparing the efficacy of a lateral-wedge insole with subtalar strapping and an in-shoe lateral-wedge insole in patients with varus deformity osteoarthritis of the knee. Arthritis Rheum 2004;50:3129-36.

26. Kuroyanagi Y, Nagura T, Matsumoto $H$, et al. The lateral wedged insole with subtalar strapping significantly reduces dynamic knee load in the medial compartment gait analysis 
on patients with medial knee osteoarthritis. Osteoarthritis Cartilage 2007;15:932-6.

27. Brouwer RW, Jakma TS, Verhagen AP, Verhaar JA, Bierma-Zeinstra SM. Braces and orthoses for treating osteoarthritis of the knee. Cochrane Database Syst Rev 2005;(1):CD004020.

28. Hanypsiak BT, Shaffer BS. Nonoperative treatment of unicompartmental arthritis of the knee. Orthop Clin North Am 2005;36:401-11.

29. Brouwer RW, van Raaij TM, Verhaar JA, Coene LN, Bierma-Zeinstra SM. Brace treatment for osteoarthritis of the knee: a prospective randomized multi-centre trial.
Osteoarthritis Cartilage 2006;14:777-83.

30. Foroughi N, Smith RM, Lange AK, Baker MK, Fiatarone Singh MA, Vanwanseele B. Dynamic alignment and its association with knee adduction moment in medial knee osteoarthritis. Knee 2010;17:210-6.

31. van den Noort JJ, van der Esch M, Steultjens MP, et al. Ambulatory measurement of the knee adduction moment in patients with osteoarthritis of the knee. J Biomech 2013;46:43-9.

32. Kutzner I, Trepczynski A, Heller MO, Bergmann G. Knee adduction moment and medial contact force-facts about their correlation during gait. PLoS One 2013;8:e81036. 